\title{
A Real Options Model to Determine the Optimal Contractual Penalty for a BOT Project*
}

\author{
João A. Ribeiro, $\ddagger_{\text {Paulo J. Pereira and Elísio M. Brandão }}$ \
}

\begin{abstract}
Public-Private Partnerships (PPP) became one of the most common types of public procurement arrangements and Build-Own-Transfer (BOT) projects, awarded through adequate bidding competitions, have been increasingly promoted by governments. The theoretical model herein proposed is based on a contractual framework where the government grants leeway to the private entity regarding the timing for project implementation. However, the government is aware that delaying the beginning of operations will lead to the emergence of social costs, i.e., the costs that result from the corresponding loss of social welfare. This fact should motivate the government to include a contractual penalty in case the private firm does not implement the project immediately. The government also recognizes that the private entity is more efficient in constructing the project facility and also in running the subsequent operations. The model's outcome is the optimal value for the legal penalty the government should include in the contract form. Sensitivity analysis reveals that there is a level for each of the comparative efficiency factors above which there is no need to impose a contractual penalty, for a given level of social costs. Finally, the effects of including a non-optimal penalty value in the contract form, which derives from overestimating or underestimating the selected bidder's real comparative efficiency are examined, using a numerical example. Results demonstrate that overestimating (underestimating) the selected bidder's real comparative efficiency leads to the inclusion of a below-optimal (above-optimal) value for the legal penalty in the contract and produces effects the government may only prevent prevent by estimating the comparative efficiency factors with full accuracy.
\end{abstract}

JEL Classification Codes: G31; D81.

Keywords: real options; option to defer; public-private partnerships; social costs; optimal contractual penalty.

https://doi.org/10.26619/UAL-CICEE/WP06.2021

*An earlier draft of this manuscript circulated under the name "A Two-Factor Uncertainty Model to Determine the Optimal Contractual Penalty for a BOT Project". The authors would like to thank Mário Coutinho dos Santos and Bruno Melo Maia for useful comments and suggestions. All errors and omissions remain ours.

${ }^{\dagger}$ Associate Professor at Universidade Autónoma de Lisboa

${ }^{\ddagger}$ Associate Researcher at CICEE - Research Center in Business and Economics; email: jribeiro@autonoma.pt

$\S$ Associate Professor at School of Economics and Management, University of Porto, Portugal; email: pjpereira@ @ep.up.pt

IFull Professor at School of Economics and Management, University of Porto, Portugal; email: ebrandao@ @ep.up.pt 


\section{Introduction}

\subsection{Build-Operate-Transfer (BOT) Projects in the Context of Bidding Competitions}

Public-Private Partnerships (PPP) became one of the most important types of public procurement arrangements and its importance has been growing considerably in the last decades (? AlonsoConde et al. (2007); Algarni et al. (2007); Ho and Liu (2002)). PPP is usually defined as a long-term development and service contract between the government and a private partner (Maskin and Tirole (2008)). This type of contract may assume different forms and the BuildOwn-Transfer (BOT) model is widely adopted (Liu and Cheah (2009); Ho and Liu (2002)). BOT is the terminology for a project structure that uses private investment to undertake the infrastructure development, and which has been historically ensured by the public sector ${ }^{1}$ In fact, the private sector has been playing an increasingly crucial role in the financing and provision of services that were traditionally in the domain of the public sector. One of the key reasons is that governments are unable to cope with the ever-increasing demands on their budgets. Most infrastructure expenditures in developing - and also in developed countries - have been funded directly from fiscal budgets but several factors such as the macroeconomic instability and growing investment needs have shown that public finance is volatile and, in many of those countries, rarely meet the infrastructure expenditure requirements in a timely and adequate manner (Ferreira and Khatami (1996)).

In BOT projects, a private entity is given a concession to build an infrastructure and operate a facility which, as we just mentioned, would traditionally be built and operated by the government or a public agent (Shen and Wu (2005)). At the end of the predetermined concession period (a period that tends to be long), the private party returns the ownership of the infrastructure to the government or the public entity (Shen et al. (2002)) $?^{2}$

BOT infrastructure projects also differ significantly from the construction projects in how they are implemented during the pre-construction phase. In the case of construction projects, the public party is responsible for project planning, property acquisition and, more importantly, project funding. For BOT projects, the concessionaire (private party) is usually required to undertake these project development tasks (Huang and Chou (2006)). This contractual arrangement provides a mechanism for using private finance, hence allowing the public sector to construct more infrastructure services without the use of additional public funds (Shen and Wu (2005)) .

\footnotetext{
${ }^{1}$ The acronym BOT is often used interchangeably with BOOT (build-own-operate-transfer). Other arrangements include BOO (build-own-operate), a type of contractual scheme where the private party does not carry the obligation of transferring the ownership in any date, meaning that the private partner may operate the facility forever, as in the case of a typical private investment project.

${ }^{2}$ Given that BOT/BOOT schemes are designed and implemented as Public-Private Partnership contractual arrangements, we will consider, for the purpose of the present work, BOT and PPP designations as being synonyms.
} 
BOT projects are awarded through an appropriate bidding competition process, where a number of private entities compete to win the contract. As with the other type of construction projects - and all other things being equal - the contract will be awarded to the bidder that presented the most competitive bid, which, in the case of BOT projects, means the bidder that offered the highest price ${ }^{3}$ The price is the amount to be paid to the government to own the right to operate the facility once the obligation of constructing the infrastructure is fulfilled. Hence, the selected bidder will be invited to sign the contract and - if the contract is actually signed - he or she will have to invest in constructing the facility and run the subsequent operations once the construction phase is completed.

\subsection{The Application of the Real Options Approach to BOT Projects}

A considerable number of research pieces can be found where the real options approach is applied to address different questions concerning BOT projects. Some of the most important issues concern project valuation, how several risk types should be shared between the parties, the role of incentives and subsidies given by the government or the public agent and also the well-known mechanism of the Minimum Revenue Guarantee (MRG). By addressing these topics using the real options approach, researchers acknowledge that this methodology seems to be the most adequate, considering that a number of real options are available to both parties throughout the life of the project. Thus, flexibility is a feature that can be frequently found on existing contracts and the levels of uncertainty surrounding this type of projects tend to be high. By recognizing the irreversibility of this type of investments and also the uncertainty and flexibility that characterizes BOT projects, some researchers adopt the real options approach to evaluate options embedded in current contract types, while others use it to sustain and propose different forms of shaping contracts between the parties, namely by suggesting that incorporating more flexibility in the contractual relationship may lead to more economic efficiency at different levels. Various research pieces can be found focusing on one or more of the above research topics. For example, Huang and Chou (2006) valued the MRG and the option to abandon the project by the private firm, and Brandao and Saraiva (2008) also developed a model for infrastructure projects based on the consideration of a Minimum Demand Guarantee. Cheah and Liu (2006) addressed the valuation of demand and revenue guarantees, applying Monte Carlo simulation, and Chiara et al. (2007) also applied the same technique to evaluate a MRG, which is only redeemable at specific moments in time. Alonso-Conde et al. (2007) addressed the existing contractual conditions in PPP which guarantee a minimum profitability to the private firm. Shan et al. (2010) proposed collar options (a call option and a put option combined) to better

\footnotetext{
${ }^{3}$ In construction projects - and all other things being equal - the selected bidder is the one that presented the lowest bid. For obvious reasons, in a BOT project competitive bid, is the other way around: all else equal, the selected bidder will be the one that offered the highest price.
} 
manage revenue risks. Huang and Pi (2009) applied a sequential compound option approach for valuing multi-stage BOT projects, in the presence of dedicated assets. Caselli et al. (2009) valued the indemnification provision that ensures a final compensation to the private partner, in the event the government terminates a BOT contract. Armada et al. (2012) showed how the net cost of incentives, which may be given by the government to induce the immediate investment, should equal the value of the option to defer the beginning of operations by the private firm.

In Section 2, we detail the proposed framework where the government grants leeway to the selected firm regarding the timing for project implementation, which means that the private firm may implement the project when he or she decides it is optimal to do so, in line with a school of thought that enhances the ability to achieve greater levels of economic efficiency in projects promoted by public authorities by managing the available options embedded in such projects, namely the option to delay the project's implementation (please see the document by the the government of New Zealand in this link:

https://www.transport.govt.nz//assets/Uploads/Paper/MOT-Real-Options.pdf)

However, and since we recognize the existence of social costs and the harmful effect to the population of delaying the project's implementation, we propose that a contractual penalty should be established in the event the private firm does not implement the project immediately. The theoretical model aims at determining the optimal level for this contractual penalty. The determination of the this optimal level will consider the argument that the selected firm is more efficient than the government in executing the project facility and running the subsequent operations and, also, that the government recognizes the existence of social costs, i.e., the costs that correspond to the loss of social welfare which will emerge if the project is not implemented immediately.

\section{Proposed Framework}

\subsection{Flexibility May Imply a Cost: The Contractual Penalty}

We define a conceptual framework where a BOT project may be undertaken by the government or awarded to a private firm through an appropriate competitive bid process, because the government recognizes that is less efficient than the private firm in executing the project and also in managing the operations once the project is completed. In fact, the recognition that the private entity is more efficient than the government is well established in the literature. We suggest that the project may be initiated whenever the selected bidder decides it is optimal to do so, meaning that no contractual obligation for immediate initiation of activities is imposed by the government. This assumption concerning the absence of any contractual obligation with 
the purpose of forcing the immediate implementation of the project has also been adopted by Armada et al. (2012), and plays a crucial role in the context of their research questions. The motivation of their research work lies on the argument that the private firm will start investing later than the government would like him or her to, since the option to delay the project's implementation does have value. Bearing this in mind, they studied how certain subsidies and guarantees, granted to the private firm, can be optimally arranged with the purpose of inducing the immediate implementation of the project. We build the present framework on the same assumption but argue that, under certain conditions, a legal penalty should be enforced in the event the construction of the facility does not start immediately. Thus, and even though we acknowledge that the private firm may manage the project implementation as far as its initiation/completion is concerned, we suggest that a penalty should be enforced in the case the infrastructure is not ready and operations do not start immediately. This means that the private firm is aware of the fact that delaying the project implementation may grant him some benefits (there is value to waiting for more information) but is also aware that delaying the beginning of the project may entail a cost. We propose that this cost should be considered in the contract form, assuming the form of a legal penalty.

\subsection{The Importance of the Private Party's Greater Efficiency}

The literature clearly acknowledges that governments are, in most cases, less efficient than private firms in conducting BOT projects. This argument is frequently invoked as being one of the reasons why governments actually grant the projects to the private sector (Brandao and Saraiva (2008); Ortiz and Buxbaum (2008); Grimsey and Lewis (2005); Zhang and Kumaraswamy (2001)). In fact, as den Hurk (2018) states, "one of the main rationales supporting the use of PPP is that the private sector is assumed to act more efficiently than the public sector. Private companies, with their own money at stake, are believed to have a strong incentive to manage projects properly; involving them in all stages of infrastructure provision would help governments achieve better value for taxpayers' money". To be more efficient means being able to construct the facility investing less money than the government would and, also, generating a greater value by running the subsequent operations. Hence, if the constructions costs of the private firm are lower than the construction costs estimated by the government, then - all else equal - the private firm will attain the critical value for the cash-flows to be generated by operations that triggers the investment sooner than the government. This is the same as saying that one expects the private firm to invest in an earlier moment of time than the government would. Yet, we also need to consider that the private fim is more efficient in running the operations, once the project facility is completed. This means that the private firm is able to extract a greater amount of profit from the project, thus resulting in a higher cash flows' trigger. This difference 
between the two parties in extracting cash flows needs to be accounted for by the government, which means that the government recognizes its less efficiency in running the operations. $4^{4}$

Considering the private firm's greater efficiency, the government's purpose is accomplished if the private firm invests when his or her cash-flows trigger equals the government cash-flows trigger, for a given level of construction costs. We would like to underline this argument: by enforcing an optimal legal penalty, the government's purpose is to induce the private firm to invest when he or she has a cash-flows trigger whose value equals the value of the government cash-flows trigger. This implies that, without the enforcement of the legal penalty, the private firm's cash-flows trigger will be higher than the government's cash-flows trigger. We will show under which conditions this inequality holds. One of these conditions derives from the fact that the government cash flows trigger is affected by another element herein considered. We designate this element as "social costs".

\subsection{The Importance of Social Costs}

The traditional concept of "social cost" was addressed by Coase (1960) and is based on the concept of "externality", in the sense that, by producing a certain good, a harmful effect is caused to the society, rather than the owners of the firm responsible for the production of that good or its customers. It is a cost which society must ultimately bear. This naturally entails that a loss of welfare occurs to the population due to the emergence of this externality. Hence, this loss of welfare is not a direct consequence of the fact that a firm is not producing a good or providing a service to its customers. Rather, social cost is exactly defined as being the cost borne by the population because a certain good is being produced and such fact causes an undesirable effect to the population. Notwithstanding, we reason that, when a government or a government agency decides to implement a project, its goal is to provide a service to the population. The government decision of, say, implementing a High-Speed Rail service is based on the conviction that the project will generate a social benefit, as stated by Rus and Nombela (2007). Hence, the government believes that social benefits occur as soon as the project is implemented and operations start because social welfare will emerge once the project is completed. Bearing this important argument in mind, we argue that, on the contrary, if the project is not implemented immediately, a loss of welfare occurs and this is the same as stating that the social benefits emerging from the immediate project implementation are postponed until the project is actually completed and the subsequent activities start. Therefore, the lack of social benefits from the moment the project should have been ready and the moment the project is, in

\footnotetext{
${ }^{4}$ Assuming that the cash flows trigger for the private firm equals 110, and that the government recognizes that is $10 \%$ less efficient than the private firm, then - all else equal - the government's cash flows trigger will be 100.
} 
fact, ready and operations begin can be legitimately defined as "social costs" 5 Social costs are, therefore, directly related with the loss of welfare that occurs if the project is not implemented immediately. Again, these costs correspond to the loss of social welfare occurred from the time the project should have been ready to start operating and providing services to its users and the moment operations actually begin and the users needs start being satisfied.

Social costs, as we define them, are rarely negligible. Large-scale investments are undertaken because governments believe that public needs must be satisfied and such needs will only be satisfied once the project is completed and subsequent operations begin. The level of the social costs may be high for some projects, moderate for other projects or even low in fewer cases. We will consider that social costs are estimated by the government as being a percentage of the expected cash-flows to be generated by operations. By estimating an expected level of social costs, the government is setting its own cash-flows trigger or, which is the same, is defining the precise moment where the project would be initiated if the government decided to undertake the project. Nevertheless, when defining the moment where the project would be implemented, the government behaves as a rational agent, in the sense that also takes into account the benefits of waiting and invest in a later date (because the government recognizes that there is value to waiting, regardless of which entity will conduct the project) and compares such benefits with the fact that, the later the project will be implemented, the higher the value of social costs will be. Thus, when the government sets its own trigger, by defining the level of social costs considered to be tolerable, the government takes into account the fact that waiting for better information does have value, The government's trigger will thus result from a tradeoff between the benefits of waiting and, hence, not invest immediately and the level of social costs to be borne by the population. We stress that, when establishing the level of social costs considered to be acceptable, the government also takes into account the benefits that derive from delaying the project implementation. Consequently, the greater the level of social costs the government considers to be acceptable, the sooner the government would invest. On the contrary, for lower levels of acceptable social costs, the government will invest later. We will numerically demonstrate the existence of this relationship later in Section 2.6.

\subsection{The Optimal Contractual Penalty}

Social costs do play a fundamental role in establishing the optimal level for the contractual penalty to be enforced in the event the project is not initiated immediately. The greater the level of social costs the sooner the government would invest and the higher the optimal penalty needs

\footnotetext{
${ }^{5}$ We would like to underline the argument that our definition of "social costs" differs from the definition of "social cost", as in Coase (1960). This means that we are not using this concept in the context of the present work since we are not considering the importance of the emergence of social cost(s), which result(s) from some kind of externality.
} 
to be, with the purpose of moving the cash-flows trigger downwards to meet the government cash-flows trigger, which is now placed more below. On the contrary, the lower the level of social costs the smaller the optimal penalty needs to be (since the government cash-flows trigger is now placed more above) and, if the level of social costs is zero, then a legal penalty is not needed, which is the same as saying that its optimal level is zero. Hence, we define the optimal value for the contractual penalty as the one that lowers the private firm's cash-flows trigger with the purpose of meeting the government cash-flows trigger, assuming that the private firm cash-flows trigger is higher than the government cash-flows trigger. Bearing this definition in mind, we have to conclude that any value for the contractual penalty that does not reduce the private firm's cash-flows trigger in order to perfectly meet the government cash-flows trigger will never be optimal. In Section 3 we will discuss the effects, to the government, of including a non-optimal level for the legal penalty in the contract form.

The remainder of the present paper unfolds as follows. In Section 2.5. the model assumptions are listed. In Section 2.6 the model is described and both the government decision to invest and the government expectation about the private firm decision to invest are presented. The optimal level for the contractual penalty "per unit" of cost is then reached, considering the effect of the estimated efficiency factors and also the effect caused by the level of social costs. In Section 2.7 we proceed to perform a sensitivity analysis, aiming to assess the impact of variations in various parameters of the model on the optimal contractual penalty. More specifically, we measure how the optimal value for the contractual penalty is affected by (i) changes in the level of social costs; (ii) changes in the efficiency factors; (iii) variations in both the level of social costs and the level of the comparative efficiency factors. Furthermore, we derive the analytical solution to the level of the efficiency factor above which the inclusion of legal penalty is not justified, for a given level of social costs. The same solution also enables us to determine the level of social costs, for a given comparative efficiency factor, above which a contractual penalty should be enforced. In Section 3 we use a numerical example in order to demonstrate the effects, to the government, of including a non-optimal value for the legal penalty in the contract from, as a result of overestimating or underestimating the comparative efficiency factors. Finally, in Section 4, concluding remarks are presented.

\subsection{Assumptions}

We assume that (i) the government has the necessary know-how to determine fair estimates about the cash-flows to be generated through operating the facility, as if the project was conducted by the government; (ii) the standard deviation of the future cash flows are the same for both the government and the private firm, since variations in the value of the project inputs and outputs are both observable in the markets; (iii) the government recognizes its less efficiency 
in two dimensions: in constructing the project facility and in running the subsequent operations; (iv) the government is capable of determining a fair estimate for the private firm's higher levels of efficiency; (v) the construction of the facility is assumed to be instantaneous: ${ }^{6}$ (vi) the project, once implemented, will generate perpetual cash-flows: $]^{7}$ (vii) the government incurs in social costs if the project is not completed and operations do not start immediately; (viii) social costs are assumed to be a percentage of the cash-flows to be generated by operations; (ix) the project dimension is given by the amount of the construction costs established by the government.

\subsection{Model Description}

\subsubsection{Introduction}

We proceed to present the base case parameter values and derive the government's decision to invest, bearing in mind that social costs are present and considered to be a percentage of the cash-flows to be generated by operations. This implies that the government recognizes the fact that, if the project is not implemented immediately, a loss of social welfare occurs until the project is completed and operations actually start running. We then derive the government's expectation about the private firm's investment decision, assuming the private firm is more efficient than the government at executing the project facility and also at running the subsequent operations, The expected construction costs are constant and designated by $K$.

For both cases, i.e., the government's decision to invest and the government's expectation about the private firm's decision to invest, the value of the cash-flows to be generated by operations follows a geometric Brownian motion $(\mathrm{gBm})$, where $G$ stand for the government and $P$ for the government's expectation about the private firm's investment decision. Being so,

$$
d V_{i}=\alpha_{i} V_{i} d t+\sigma_{i} V_{i} d z_{i}
$$

where $\alpha_{i}$ is the drift parameter, $d t$ is the time interval, $\sigma_{i}$ is the standard deviation for the cash flows, $d z_{i}$ and is the increment of a standard Wiener process. Under risk-neutrality, being $r$ the risk-free interest rate, then $\delta$, the cash flows' rate of return shortfall is given by the following equation:

\footnotetext{
${ }^{6} \mathrm{By}$ assuming that the construction of the facility is instantaneous, we are implicitly considering that no flexibility is present throughout the construction stage. Therefore, we exclude the existence of options during this stage.

${ }^{7} \mathrm{We}$ assume that the concession period is sufficiently long for the investment opportunity to be considered equivalent to a perpetual call option. This is a common assumption in the literature. See, for example, Armada et al. (2012).
} 


$$
\delta=r-\alpha
$$

Table 1 includes the base case parameter values we will be using, unless otherwise mentioned.

Table 1: the base case parameter values

$($ for $i \in\{G, P\})$
\begin{tabular}{|c||c||c|}
\hline Parameters & Symbols & Values \\
\hline \hline standard deviation of the cash-flows & $\sigma_{i}$ & 0.15 \\
\hline \hline cash-flows' rate of return-shortfall & $\delta_{i}$ & 0.03 \\
\hline \hline risk-free interest rate & $r$ & 0.05 \\
\hline \hline level of social costs & $s$ & 0.02 \\
\hline \hline construction costs' comparative efficiency factor & $\varphi$ & 0.1 \\
\hline cash-flows' comparative efficiency factor & $\Theta$ & 0.1 \\
\hline
\end{tabular}

\subsubsection{The Government's Decision to Invest}

In the presence of social costs, the value of the government investment opportunity, $F_{G}\left(V_{G}\right)$ must satisfy the following ordinary differential equation :

$$
\frac{1}{2} \sigma_{G}^{2} V_{G}^{2} \frac{\partial^{2} F_{G}}{\partial V_{G}^{2}}+(r-\delta) V_{G}^{2} \frac{\partial F_{G}}{\partial V_{G}}-r F_{G}-s V_{G}=0
$$

where $s V_{G}$ denotes the value of social costs as a percentage of the cash-flows to be generated by the project's operations. The following solution satisfies the ordinary differential equation (2):

$$
F_{G}\left(V_{G}\right)=A_{1} V_{G}^{\beta^{+}}+A_{2} V_{G}^{\beta^{-}}-\frac{s}{\delta} V_{G}
$$

where $\beta^{+}$and $\beta^{-}$are the roots of the following quadratic equation:

$$
Q(\beta)=\frac{1}{2} \sigma_{G}^{2} \beta(\beta-1)+\left(r-\delta_{G}\right) \beta-r=0
$$


We are only interested in $\beta^{+}$, i.e., the root of the fundamental quadratic equation (5) whose value exceeds one ${ }^{8} \beta^{+}$is determined by the following expression:

$$
\beta^{+}=\frac{1}{2}-\frac{r-\delta}{\sigma^{2}}+\sqrt{\left(\frac{r-\delta}{\sigma^{2}}-\frac{1}{2}\right)+\frac{2 r}{\sigma^{2}}}
$$

Being so, equation (4) becomes reduced and the solution for the ordinary differential equation takes the following form:

$$
F_{G}\left(V_{G}\right)=A_{1} V_{G}^{\beta^{+}}-\frac{s}{\delta} V_{G}
$$

where $A_{1}$ is a constant that is yet to be determined. According to Dixit and Pindyck (1994), there are two other boundary conditions that must be satisfied.

The second boundary condition is the value-matching condition, which implies that when the cash flows' trigger $\left(V_{G}^{*}\right)$ is attained, the value of the option to invest must equal the project's expected Net Present Value. Therefore, the value-matching condition is as follows:

$$
F_{G}\left(V_{G}^{*}\right)=A_{1} V_{G}^{*^{+}}-\frac{s}{\delta} V_{G}^{*}=V_{G}^{*}-K_{G}
$$

The last boundary condition is the smooth-pasting condition, which is the first-order derivative of the value-matching condition, in respect to $V_{G}^{*}$, assuring that $F_{G}\left(V_{G}\right)$ is continuously differentiable along $V_{G}$ :

$$
F_{G}^{\prime}\left(V_{G}^{*}\right) \quad=\beta^{+} A_{1} V_{G}^{*^{\beta^{+}}-1}-\frac{s}{\delta}=1
$$

Substituting and rearranging, we reach the expression for the government's cash flow trigger:

$$
V_{G}^{*}=\frac{\beta^{+}}{\beta^{+}-1} \frac{K_{G}}{\left(1+\frac{s}{\delta}\right)}
$$

And the corresponding value-function is:

\footnotetext{
${ }^{8}$ Please refer to Dixit and Pindyck $(1994)$ for further details.
} 


$$
F_{G}\left(V_{G}\right)=\left\{\begin{array}{llll}
\left(V_{G}^{*}-K_{G}\left(\frac{V_{G}}{V_{G}^{*}}\right)^{\beta^{+}}\right. & \text {if } & V_{G}<V_{G}^{*} \\
V_{G}-K_{G} & \text { if } & V_{G} \geq V_{G}^{*}
\end{array}\right.
$$

\subsubsection{The Government's Expectation about the Private Firm's Investment Decision}

Since we assume that private firm is more efficient than the government in undertaking the project, the private firm's construction costs need to be lower than the government's constructions costs. Being so, let $\phi$ denote this comparative efficiency factor. We can relate the construction costs of both entities using the following equation:

$$
K_{P}=K_{G}(1-\phi)
$$

We now proceed to compute the trigger values of the private firm as estimated by the government. The firm may face a contractual penalty, which we denote by $C$, for delaying the project's implementation. Let $F_{P}\left(V_{P}\right)$ denote the government's expectation about the value of the private firm's investment opportunity. $F_{P}\left(V_{P}\right)$ must satisfy the following ordinary differential equation:

$$
\frac{\mathbf{1}}{2} \sigma_{V_{P}}^{2} V_{P}^{2} \frac{\partial^{2} F_{P}}{\partial V_{P}^{2}}+(r-\delta) V_{P}^{2} \frac{\partial F_{P}}{\partial V_{P}}-r F_{P}-C=0
$$

The following expression is the solution for the ordinary differential equation (14):

$$
F_{P}\left(V_{P}\right)=A_{2} V_{P}^{\beta^{+}}-\frac{C}{r}
$$

As in the previous case, we are only interested in the root of the quadratic equation that exceeds one. Thus the solution to equation (14) becomes reduced to:

$$
F_{P}\left(V_{P}\right)=A_{2} V_{P}^{\beta^{+}}-\frac{C}{r}
$$

The value-matching condition is: 


$$
F_{P}\left(V_{P}^{*}\right)=A_{2} V_{P}^{*^{+}}-\frac{C}{r}=V_{P}^{*}-K_{P}
$$

The other boundary condition is the smooth-pasting condition. This condition is the first-order derivative of the value-matching condition, in respect to $V_{P}^{*}$, which ensures that the function is continuously differentiable along

$$
F_{P}^{\prime}\left(V_{P}^{*}\right)=\beta^{+} A V_{P}^{*^{\beta^{+}}-1}=1
$$

After substitution and also applying some rules of calculus, we obtain the expression for the private firm cash flows' trigger:

$$
V_{P}^{*}=\frac{\beta^{+}}{\beta^{+}-1}\left(K_{P}-\frac{C}{r}\right)
$$

The corresponding value-function is as follows:

$$
F_{P}\left(V_{P}\right)=\left\{\begin{array}{llll}
\left(V_{P}^{*}-K_{P}-\frac{C}{r}\right)\left(\frac{V_{P}}{V_{P}^{*}}\right)^{\beta^{+}} & & \text {if } & V_{P}<V_{P}^{*} \\
V_{P}-K_{P} & \text {; if } & & V_{P} \geq V_{P}^{*}
\end{array}\right.
$$

Since the private entity is, in most cases, more efficient than the government in managing the operations, we need another comparative efficiency factor to express this greater efficiency. Being so, let $\theta$ denote this comparative efficiency factor and $V_{G}^{+}$denote the private firm's cashflows trigger as if the government would invest when the private firm's cash flows trigger is attained. This means that the government estimates the private firm's cash flows trigger and affects it by the comparative efficiency factor, $\theta$. We designate this trigger by $V_{G}^{+}$, which is given by the following equation:

$$
V_{G}^{+}=\frac{\beta^{+}}{\beta^{+}-1}\left(K_{P}-\frac{C}{r}\right) \frac{1}{(1+\theta)}
$$

Pease note that $V_{G}^{+}$and $V_{P}^{*}$ differ by the factor $\frac{1}{(1+\theta)}$. This difference is caused by the fact that the 
private firm's cash flows trigger is not affected by the comparative efficiency factor, $\theta$, whereas the government's cash-flows trigger, $V_{G}^{+}$needs to be. The government, in order to incorporate the private firm's greater efficiency in its decision-making process, needs to multiply the private firm's cash flow trigger by $\frac{1}{(1+\theta)}$. Hence, one can establish the following relationship between these two triggers:

$$
V_{G}^{+}=\frac{V_{P}^{*}}{(1+\theta)}
$$

Equation (22) implies that the private firm's real cash flows trigger will always be greater than the private firm's cash- flows trigger as computed by the government. In fact, from equation 22, we arrive at $V_{P}^{*}=V_{G}^{+}(1+\theta)$, reflecting the private firm's greater efficiency in running the operations.

\subsubsection{Determining the Optimal Value for the Contractual Penalty}

Let $V_{G}^{-}$denote private firm's cash- flows' trigger as seen by the government in the absence of any contractual penalty. This means that $V_{G}^{+}$is the same trigger but already affected by the inclusion of the optimal contractual penalty. Since the optimal value for the contractual penalty, $C^{*}$, is the one that makes both triggers have the same value, then we have to align both triggers, ie., $V_{G}^{*}=V_{G}^{+}$. The analytical solution for the optimal contractual penalty, $C^{*}$, is as follows:

$$
C^{*}=r K_{P}\left[\frac{s}{s+\delta}-\frac{\delta}{s+\delta} \frac{\theta+\phi}{1-\phi}\right]
$$

The optimal contractual penalty is a function of the risk-free rate, the private firm's level of construction costs, both comparative efficiency factors, the estimated level of social costs and the cash flows' rate of return shortfall. We should underline the fact that changes in the volatility parameter have no impact on the level for the optimal contractual penalty.

After some substitutions and rearranging, we reach the final equation for the private entity's cash-flow trigger after considering the enforcement of the optimal penalty, $C^{*}$ :

$$
V_{P}^{*}=K_{P} \frac{\beta}{\beta-1} \frac{\delta}{s+\delta} \frac{1+\theta}{1-\phi}
$$


Table (2) depicts the results for the government's cash-flows trigger, $V_{G}^{*}$, the private firm's cash flows trigger as if the government would invest when the private firm's cash flows trigger is attained, $V_{G}^{+}$, and the optimal contractual penalty, for three possible project dimensions, given by $K_{G}=100, K_{G}=200$ and $K_{G}=300$.

Table 2: representative values for the three cash flows triggers, and the optimal contractual penalty, considering three project dimensions

(for: $\sigma=0.15 ; r=0.05 ; \delta=0.03 ; s=0.02 ; \varphi=0.1 ; \theta=0.1$ )

\begin{tabular}{|c||c||c||c|c||c||c|c|c|}
\hline$K_{G}$ & $K_{P}$ & $V_{G}^{*}$ & $V_{G}^{-}$ & $c^{*}$ & $V_{G}^{+}$ & $V_{P}^{*}$ & $c * / K_{G}$ & $c * / K_{P}$ \\
\hline \hline 100 & 90 & 139 & 163 & 1.2 & 139 & 153 & 0.012 & 0.0133 \\
\hline \hline $\mathbf{2 0 0}$ & $\mathbf{1 8 0}$ & $\mathbf{2 7 9}$ & 380 & $\mathbf{2 . 4}$ & 279 & 307 & 0.012 & 0.0133 \\
\hline \hline 300 & 270 & 419 & 571 & 3.6 & 419 & 460 & 0.012 & 0.0133 \\
\hline
\end{tabular}

Results in Table 2 clearly show that the level of the optimal contractual penalty, $c^{*}$ is proportional to the level of $K_{G}$ and, consequently, also proportional to the level of $K_{P}$. This means that no scale-effect is present in the model: an increase (decrease) in the construction costs trigger will lead to an increase (decrease) in the value of the optimal legal penalty of the same magnitude. This proportionality feature allows us to determine the level of the optimal contractual penalty "per unit" of the private firm's construction costs which, according to the inputs considered, equals 0.133 . Please note that $V_{P}^{*}$ equals $V_{G}^{+}$multiplied by $1+\theta$, hence placing the trigger of the private firm higher due to the effect of its greater efficiency in running the operations. We also remind that $V_{G}^{-}$is the private firm's cash flows trigger computed by the government before considering the inclusion of any contractual penalty.

\subsection{Sensitivity Analysis}

\subsubsection{The Impact of Social Costs on the Optimal Contractual Penalty}

Table 3 includes a set of values for the social costs and their impact on the government cashflows trigger and on the optimal contractual penalty, assuming the project dimension given by $K_{G}^{*}=200$. 
Table 3: sensitivity analysis: the impact of the level of social costs on the optimal contractual penalty

(for: $\sigma=0.15 ; \delta=0.02 ; r=0.05 ; \phi=0.1 ; \theta=0.1$ )

\begin{tabular}{|c||c||c||c||c||c|}
\hline$K_{G}$ & $K_{P}$ & $s$ & $V_{G}^{*}$ & $c *$ & $V_{G}^{+}$ \\
\hline \hline 200 & 180 & 0 & 465 & 0.000 & 380 \\
\hline \hline 200 & 180 & 0.005 & 399 & 0.000 & 419 \\
\hline \hline $\mathbf{2 0 0}$ & $\mathbf{1 8 0}$ & $\mathbf{0 . 0 0 6 7}$ & $\mathbf{3 8 1}$ & $\mathbf{0 . 0 0 0}$ & $\mathbf{3 8 1}$ \\
\hline \hline 200 & 180 & 0.01 & 349 & 0.7500 & 349 \\
\hline \hline 200 & 180 & 0.015 & 310 & 1.6666 & 310 \\
\hline \hline 200 & 180 & 0.02 & 279 & 2.4000 & 279 \\
\hline \hline 200 & 180 & 0.25 & 232 & 3.5000 & 232 \\
\hline
\end{tabular}

Given comparative efficiency factors of $\phi=0.1$ and $\theta=0.1$, for values of $s \leq 0.0067$ there is no need to enforce a legal penalty because $V_{G}^{+}$is lower than (or equal to) $V_{G}^{*}$. For $s>$ 0.0067, the higher the level of social costs the lower the government cash flows trigger, which means that the difference between $V_{G}^{+}$and the government's cash flows trigger, $V_{G}^{*}$, becomes greater. Consequently, a stronger contractual penalty is needed in order to perfectly align the two triggers. This also implies that there is a specific level of social costs that makes both cash flows triggers have the same value, before considering the effect of any contractual penalty. Such level of social costs is, therefore, the threshold value below which the inclusion of a contractual penalty is not necessary. We can derive an analytical solution to determine this threshold value, which we designate by $\bar{s}$. Thus, $\tilde{s}$ will be given by the following equation:

$$
\bar{s}=\delta\left(1+\frac{1+\theta}{1-\phi}\right)
$$

\subsubsection{The Impact of the Efficiency Factors on the Optimal Contractual Penalty}

Table 4 includes a set of different values for the construction costs' comparative efficiency factor, $\phi$ and its impact on the optimal contractual penalty, assuming that the project dimension is given by $K_{G}=200$. We set the other comparative efficiency factor, $\theta$ to 0.1 . 
Table 4: sensitivity analysis: the impact of the construction costs' efficiency factor on the optimal contractual penalty

$$
\text { (for: } \sigma=0.15 ; \delta=0.03 ; ; r=0.05 ; s=0.02 ; \theta=0.1 \text { ) }
$$

\begin{tabular}{|c|c||c||c||c||c|c|}
\hline$\phi$ & $K_{G}$ & $K_{P}$ & $V_{G}^{*}$ & $c *$ & $V_{G}^{+}$ & $V_{P}^{*}$ \\
\hline \hline 0.0 & 200 & 200 & 279 & 3,4 & 279 & 307 \\
\hline \hline 0.1 & 200 & 180 & 279 & 2,4 & 279 & 307 \\
\hline \hline 0.2 & 200 & 160 & 279 & 1,4 & 279 & 307 \\
\hline \hline 0.25 & 200 & 150 & 279 & 0,9 & 279 & 307 \\
\hline \hline 0.3 & 200 & 140 & 279 & 0,4 & 279 & 307 \\
\hline \hline $\mathbf{0 . 3 4}$ & $\mathbf{2 0 0}$ & $\mathbf{1 2 0}$ & $\mathbf{2 7 9}$ & $\mathbf{0}$ & $\mathbf{2 7 9}$ & $\mathbf{3 0 7}$ \\
\hline \hline 0.4 & 200 & 120 & 279 & 0 & 257 & 307 \\
\hline \hline
\end{tabular}

Results included in Table 4 show that a higher efficiency factor leads to lower levels for the optimal contractual penalty, $C^{*}$. Moreover, there is a value for this efficiency factor above which there is no need to include a contractual penalty in the contract form. In fact, when $\phi$ is lower or equal to $0.34, V_{G}^{+}$will be equal or lower than $V_{G}^{*}$, meaning that there is no need for any contractual penalty since the government's purpose is already accomplished. In such cases, the optimal contractual penalty is zero.

We can derive an analytical solution to obtain the level below which the inclusion of a legal penalty in the contract form is justified. Let $\bar{\phi}$ denote the level for the comparative efficiency factors that align both triggers: this is the level below which a legal penalty should be enforced. $\bar{\phi}$ will be given by the following equation:

$$
\bar{\phi}=1-\frac{1+\frac{S}{\delta}}{1+\theta}
$$

Table 5 includes a set of different values for the cash flows' comparative efficiency factor, $\theta$ and its impact on the optimal contractual penalty, assuming that the project dimension is given by $K_{G}=200$. We set the other comparative efficiency factor, $\phi$, to 0.1 . 
Table 5: sensitivity analysis: the impact of the cash flows' efficiency factor on the optimal contractual penalty

$$
\text { (for: } \sigma=0.15 ; \delta=0.03 ; ; r=0.05 ; s=0.02 ; \phi=0.1 \text { ) }
$$

\begin{tabular}{|c|c||c||c||c||c|c|}
\hline$\theta$ & $K_{G}$ & $K_{P}$ & $V_{G}^{*}$ & $c *$ & $V_{G}^{+}$ & $V_{P}^{*}$ \\
\hline \hline 0.0 & 200 & 190 & 279 & 3.0 & 279 & 279 \\
\hline \hline 0.1 & 200 & 190 & 279 & 2.4 & 279 & 307 \\
\hline \hline 0.2 & 200 & 190 & 279 & 1.8 & 279 & 335 \\
\hline \hline 0.3 & 200 & 190 & 279 & 1.2 & 279 & 363 \\
\hline \hline 0.4 & 200 & 190 & 279 & 0.6 & 279 & 391 \\
\hline \hline $\mathbf{0 . 5}$ & $\mathbf{2 0 0}$ & $\mathbf{1 9 0}$ & $\mathbf{2 7 9}$ & $\mathbf{0}$ & $\mathbf{2 7 9}$ & $\mathbf{4 1 9}$ \\
\hline \hline 0.6 & 200 & 190 & 279 & 0 & 279 & 446 \\
\hline
\end{tabular}

Results included in Table 5 also demonstrate that a higher efficiency factor leads to lower levels for the optimal contractual penalty, $C^{*}$. We also conclude that there is a value for the efficiency factor above which there is no need to include a contractual penalty in the contract form. Like in the previous case, when this efficiency factor assumes values equal or greater than $0.5, V_{G}^{+}$ will be equal or lower than $V_{G}^{*}$, meaning that there is no need to include a legal penalty in the contract, since the government's purpose is already accomplished. In such cases, the optimal contractual penalty should be zero. Being so, we can derive an analytical solution to obtain the level below which the inclusion of a legal penalty in the contract form is justified. Let $\bar{\theta}$ denote the level for the comparative efficiency factors that align both triggers: this is the level below which a legal penalty should be enforced. Being so, $\bar{\theta}$ will be given by the following equation:

$$
\bar{\theta}=(1-\phi)\left(1+\frac{s}{\delta}\right)-1
$$

\subsubsection{The Combined Impact of the Level of Social Costs and the Level of the Efficiency Factor on the Optimal Contractual Penalty}

We will now demonstrate how the level of social costs, combined with the level of the comparative efficiency, affect the optimal contractual penalty. As shown in Table 3above, the greater the level of social costs the lower the government cash-flows trigger. The government cash-flows trigger is thus shifted downwards due to the existence of social costs, pressuring the government to invest sooner. However, we now have to confront the government cash-flows trigger, affected 
by a set of different levels for the social costs, with the private firm's cash-flows trigger, affected by different levels of comparative efficiency. We emphasize that the optimal contractual penalty is the one that moves the private firm cash-flows trigger downwards with the purpose of perfectly meeting the government cash-flows trigger, for any dimension the project may assume. For the sake of simplicity, we will consider that both efficiency factors assume the same level. The project dimension is again given by $K_{G}=200$.

Table 6: sensitivity analysis: the combined impact of the level of social costs and the level of the efficiency factors on the optimal contractual penalty

$$
\text { (for: } \sigma=0.15 ; r=0.05 ; \delta=0.03 ; K_{G}=200 \text { ) }
$$

\begin{tabular}{|c||c|c|c||c||c||c||c|}
\hline & $s=0.00315$ & $s=0.005$ & $s=0.01$ & $s=\mathbf{0 . 0 2}$ & $s=0.03$ & $s=0.04$ & $s=0.05$ \\
\hline \hline$(\phi ; \theta)=0.05$ & 0 & 0.500 & 1.625 & 3.200 & 4.250 & 5.000 & 5.563 \\
\hline \hline$(\phi ; \theta)=\mathbf{0 . 1 0}$ & 0 & 0 & 0.750 & $\mathbf{2 . 4 0 0}$ & 3.500 & 4.286 & 4.875 \\
\hline \hline$(\phi ; \theta)=0.15$ & 0 & 0 & 0 & 1.600 & 2.750 & 3.571 & 4.188 \\
\hline \hline$(\phi ; \theta)=0.20$ & 0 & 0 & 0 & 0.800 & 2.000 & 2.857 & 3.500 \\
\hline \hline$(\phi ; \theta)=0.25$ & 0 & 0 & 0 & 0 & 1.250 & 2.143 & 2.813 \\
\hline \hline$(\phi ; \theta)=0.30$ & 0 & 0 & 0 & 0 & 0.500 & 1.429 & 2.125 \\
\hline \hline$(\phi ; \theta)=0.35$ & 0 & 0 & 0 & 0 & 0 & 0.714 & 1.438 \\
\hline \hline$(\phi ; \theta)=0.40$ & 0 & 0 & 0 & 0 & 0 & 0 & 0.750 \\
\hline
\end{tabular}

The values included in Table 6 are the optimal values for the contractual penalty that result from considering combinations for the level of social costs and the efficiency factors. The results clearly illustrate that the greater the level of social costs the higher the value of the optimal legal penalty, for a given level of efficiency factors and, the higher the efficiency factors, the lower the value of the optimal penalty, for a given level of social costs. However, when the comparative efficiency factors are equal to or higher than 0.40 and the level of social costs is equal to or lower than 0,04 , there is no need to impose a legal penalty in the contract form because the combination of the two factors is strong enough to align the cash-flows triggers. This is the reason why, in such cases, the optimal contractual penalty is zero. 


\section{The Effects, to the Government, of a Including a Non-Optimal Value for the Legal Penalty in the Contract Form}

The model herein suggested proposes a method to determine the optimal level for the contractual penalty, from the government perspective. Based on its own estimates about the value of cash-flows to be generated from managing operations, the level of social costs and the comparative efficiency factors, the government is able to reach the value for the optimal contractual penalty "per unit" of the government's construction costs. This optimal contractual penalty moves the private firm's cash-flows trigger (as seen by the government) downwards in order to meet the government cash-flows trigger.

In the context of BOT project, a bidding process takes place and all bidders have access to the contractual rules included in the bid documents provided to all the participants. Bidders prepare their proposals taking into account the presence of the contractual penalty established by the government and compute their bid prices accordingly. Sometime after, one of the bidders is selected and invited to sign the contract and, consequently, to invest in executing the project facility and run the subsequent activities.

Yet, one may consider that the value of the legal penalty included in the contract form is not optimal because the government might have inaccurately estimated the selected bidder comparative efficiency factors. In fact, it is possible that the government has determined the value of the contractual penalty assuming a set of comparative efficiency factors that are different from the selected bidder's real comparative efficiency factors. Such possibility motivates us to examine the effects that overestimating/underestimating the efficiency factors will produce, from the government's perspective.

We will present each of the two non-optimal scenarios separately, i.e., first we discuss the scenario where the government overestimated the selected bidder comparative efficiency factors and, after, the scenario where the selected bidder efficiency factor is greater than the government expected. Again, since the efficiency factors play a crucial role in determining the optimal value for the legal penalty, any difference that may occur between the efficiency factors estimated by the government and the selected bidder's real comparative efficiency necessarily means that the value of the legal penalty included in the contract will not be optimal.

\subsection{The Effects of Overestimating the Comparative Efficiency Factors}

Table 8 includes a set of representative values aiming to demonstrate the effects, to government, of overestimating the comparative efficiency factors. Again, we assume that the project dimension is given by $K_{G}^{*}=200$. We also assume, for comparison purposes, the base case values for 
the efficiency factors as being the real efficiency factors, i.e., $(\phi=0.1 ; \theta=0.1)$. Please note that $F\left(V_{P}^{*}\right)=V_{P}^{*}-K_{P}$ because when the trigger is attained, the value of the option to invest equals the project's expected Net Present Value.

Table 7: the effects, to the government, of overestimating the comparative efficiency factors

\begin{tabular}{|c|c|c|c|c|c|c|c|c|c|}
\hline & $V_{G}^{*}$ & $V_{G}^{-}$ & $C^{*}$ & $V_{G}^{+}$ & $V_{P}^{*}$ & $K_{G}$ & $K_{P}$ & $F\left(V_{G}^{*}\right)$ & $F\left(V_{P}^{*}\right)$ \\
\hline$(\phi ; \theta)=\mathbf{0 . 1}$ & 279 & 380 & 2.4 & 279 & 307 & 200 & 180 & 79 & 127 \\
\hline$(\phi ; \theta)=0.15$ & 279 & 380 & 1.6 & 313 & 344 & 200 & 170 & 79 & 174 \\
\hline$(\phi ; \theta)=0.2$ & 279 & 380 & 0.8 & 347 & 381 & 200 & 160 & 79 & 201 \\
\hline
\end{tabular}

Assuming that the real efficiency factors are $\phi=0.1 ; \theta=0.1$, the optimal contractual penalty is $C^{*}=2.4$ because this is the value for the legal penalty that moves the selected bidder cashflows trigger (as computed by the government), $V_{G}^{-}=380$ downwards to perfectly meet the government cash-flows trigger, $V_{G}^{+}=V_{G}^{*}=279$. The results above show that overestimating the comparative efficiency factors results in the inclusion of a below-optimal contractual penalty in the contract, leading the selected bidder cash-flows trigger, $V_{G}^{+}$to be placed above the government cash-flows trigger. In fact, for an overestimation of 0.05 , resulting in establishing $\phi=0.5 ; \theta=0.15$ for the comparative efficiency factors, the contractual penalty will be $C=1.6$. This value for the contractual penalty fails to shift downwards $V_{G}^{-}$in order to meet $V_{G}^{*}$. In fact, $V_{G}^{+}$equals 313 , a value above the government's cash flows trigger, which is equal to 279 .

This incapacity shown by the contractual penalty of perfectly shifting downwards $V_{G}^{-}$in order to meet $V_{G}^{*}$ has another consequence: the bidder's option to invest, $F\left(V_{P}^{*}\right)$ is now more valuable. Since we believe that rational bidders will offer higher prices as a direct consequence of holding a more valuable option to invest, the government would, therefore, obtain a greater revenue. However, the additional revenue the government would receive would also entail a cost. In fact, by investing later, the level of social costs the population would have to bear will be greater. We argue that the government would prefer to receive a lower revenue and ensure that the value of social costs, previously defined as being tolerable, would not be exceeded.

\subsection{The Effects of Underestimating the Comparative Efficiency Factors}

Table 9 includes a set of representative values aiming to demonstrate the effects, to government, of underestimating the comparative efficiency factors. Again, we assume that the project di- 
mension is given by $K_{G}^{*}=200$ and the base case values for the efficiency factors are the real efficiency factors, i.e., $(\phi ; \theta=0.1)$.

Table 8: the effects, to the government, of underestimating the comparative efficiency factors

\begin{tabular}{|c|c|c|c|c|c|c|c|c|c|}
\hline & $V_{G}^{*}$ & $V_{G}^{-}$ & $C^{*}$ & $V_{G}^{+}$ & $V_{P}^{*}$ & $K_{G}$ & $K_{P}$ & $F\left(V_{G}^{*}\right)$ & $F\left(V_{P}^{*}\right)$ \\
\hline$(\phi ; \theta)=\mathbf{0 . 1}$ & 279 & 380 & 2.4 & 279 & 307 & 200 & 180 & 79 & 127 \\
\hline$(\phi ; \theta)=0.075$ & 279 & 380 & 2.8 & 262 & 288 & 200 & 180 & 79 & 108 \\
\hline$(\phi ; \theta)=0.05$ & 279 & 380 & 3.2 & 245 & 270 & 200 & 180 & 79 & 90 \\
\hline
\end{tabular}

By underestimating the comparative efficiency factors, the government includes an aboveoptimal penalty in the contract form. This fact results in the inability to align the two triggers. This time, the trigger is shifted downwards to be placed below the government's cash flows trigger. This fact is visible in the table below. For example, for an underestimation of 0.05 , the comparative factors are $\{\phi ; \theta\}=0.05$ and the non-optimal contractual penalty will be $C=3.2$. This value for the contractual penalty is to strong and thus shift downwards $V_{G}^{-}$to equal 262, a value way below the government's cash flows trigger, which equals 279 .

As in the previous case, the inclusion of non-optimal contractual penalty changes the value of the bidders's option to invest, $F\left(V_{P}^{*}\right)=108$, a value that compares with 127 , which is the option value in the accurate scenario. This means that the bidder possesses an option to invest that is less now valuable. Being so, one should expect him or her to establish a lower bid price and, consequently, after the bidder is selected and the contract is actually signed, the government will receive less money. This is obviously an effect that governments should prevent since the price paid by the selected bidder will be lower than the price offered if the comparative efficiency factors were estimated with full accuracy.

\section{Concluding Remarks}

The suggested model is based on a contractual framework, in the context of a BOT project, where the government grants leeway to the selected bidder regarding the timing for the project implementation, thus recognizing that, regardless of the entity that will conduct the project, there is value of waiting to invest. However, this flexibility may entail a cost, since a legal penalty is contractual enforced if the selected bidder does not implement the project immediately. With the purpose of determining the optimal value for this contractual penalty, we considered that the government is less efficient than the private firm in constructing the project facility 
and we have also considered the existence of social costs, i.e., the costs that correspond to the loss of social welfare occurred from the moment the project should have been implemented and services being provided to its users and the moment the project is actually completed. The government's purpose is to ensure that the selected bidder will invest when his or her cash-flows trigger has the same value of the government cash-flows trigger, if the government decided to conduct the project.

To determine the optimal level for the contractual penalty, we derived the government decision to invest and the government expectation about the private firm's decision to invest. We then reached an optimal level for the contractual penalty "per unit" of cost, since there is proportionality between the optimal value for the contractual penalty and the amount of the construction costs.

Sensitivity analysis performed demonstrated that the greater the level of social costs the sooner one expects the government would invest, higher levels of social costs result in lower values for the government cash-flows trigger. The analysis also revealed that there is a level for each of the comparative efficiency factors above which there is no need to include a penalty in the contract, since such level of the efficiency factor, for the level of social costs considered, naturally moves the private firm cash-flows trigger downwards to perfectly meet the government cash-flows trigger.

Finally, we examined the effects that overestimating or underestimating the comparative efficiency factor produces in the value of the optimal contractual penalty. We concluded that overestimating the efficiency factor results in the determination of a below-optimal value for the contractual penalty, and that underestimating this same factor will lead to the inclusion of an-above optimal value for the legal penalty in the contract form. In both cases, the government will face undesirable consequences which can only be prevented if the comparative efficiency factors are estimated with full accuracy. 


\section{References}

Algarni, A. M., D. Arditi, and G. Polat: (2007), 'Build-Operate-Transfer in Infrastructure Projects in the United States'. Journal of Construction Engineering and Management pp. 728-735.

Alonso-Conde, A., C. Brown, and J. Rojo-Suarez: (2007), 'Public-Private Partnerships: Incentives, Risk Transfer and Real Options'. Review of Financial Economics pp. 335-349.

Armada, M. J. R., P. J. Pereira, and A. Rodrigues: (2012), 'Optimal Subsidies and Guarantees in PublicPrivate Partnerships'. The European Journal of Finance pp. 469-495.

Brandao, L. E. and E. Saraiva: (2008), 'The Option Value of Government Guarantees in Infrastructure Projects'. Construction Management and Economics pp. 1171-1180.

Caselli, S., S. Gatii, and A. Marciante: (2009), 'Pricing Final Indemnification Payments to Private Sponsors in Project-Financed Public-Private Partnerships: An Application of Real Options Valuation'. Journal of Applied Corporate Finance pp. 95-106.

Cheah, C. and J. Liu: (2006), 'Valuing Governmental Support in Infrastructure Projects as Real Options Using Monte Carlo Simulation'. Construction Management and Economics pp. 515-54.

Chiara, N., M. J. Garvin, and J. Vecer: (2007), 'Valuing Simple Multiple-Exercise Real Options in Infrastructure Projects'. Journal of Infrastructure Systems pp. 97-104.

Coase, R. H.: (1960), 'The Problem of Social Cost'. Journal of Law and Economics pp. 1-44.

den Hurk, M. V.: 2018, 'Public-Private Partnerships: Where Do We Go From Here? A Belgian Perspective'. Public Works Management and Policy 23(3), 274-294.

Dixit, A. and R. Pindyck: (1994), Investment Under Uncertainty. New Jersey: Princeton University Press.

Ferreira, D. and K. Khatami: (1996), 'Financing Private Infrastructure in Developing Countries'. World Bank - Discussion Papers 343, 1-32.

Grimsey, D. and M. K. Lewis: 2005, 'Are Public-Private Partnesrships Value for Money? Evaluating Alternative Approaches and Comparing Academic and Practitioner Views'. Accounting Forum 29, $345-378$.

Ho, S. P. and L. Y. Liu: (2002), 'An Option Pricing-Based Model for Evaluating the Financial Viability of Privatized Infrastructure Projects'. Construction Management and Economics pp. 143-156.

Huang, Y. and S. Chou: (2006), 'Valuation of the Minimum Revenue Guarantee and the Option to Abandon in BOT Infrastructure Projects'. Construction Management and Economics pp. 379-389. 
Huang, Y.-L. and C.-C. Pi: (2009), 'Valuation of Multi-Stage BOT Projects Involving Dedicated Asset Investments: A Sequential Compound Option Approach'. Construction Management and Economics pp. 653-666.

Liu, J. and C. Y. J. Cheah: (2009), 'Real Option Application in PPP/PFI Project Negotiation'. Construction Management and Economics 27(4), 331-342.

Maskin, E. and J. Tirole: (2008), 'Public-Private Partnerships and Government Spending Limits'. International Journal of Industrial Organization pp. 412-420.

Ortiz, I. N. and J. N. Buxbaum: 2008, 'Protecting the Public Interest in Log-Term Concession Agreements for Transportation Infrastructure'. Public Works Management and Policy 13, 126-137.

Rus, G. and G. Nombela: (2007), 'Is Investment in High Speed Rail Socially Profitable?'. Journal of Transport Economics and Policy pp. 3-23.

Shan, L., M. Garvin, and R. Kumar: (2010), 'Collar Options to Manage Revenue Risks in Real Toll Public-Private Partnership Transport Projects'. Construction Management and Economics pp. 10571059.

Shen, L. and Y. Z. Wu: (2005), 'Risk Concession Model for Build-Operate-Transfer Contract Projects' . Journal of Construction Engineering and Management pp. 211-220.

Shen, L. Y., H. LI, and Q. M. Li: (2002), 'Alternative Concession Model for Build Operate Transfer Contract Projects'. Journal of Construction Engineering and Management pp. 326-330.

Zhang, X. Q. and M. M. Kumaraswamy: (2001), 'Procurement Protocols for Public-Private Partnered Projects'. Journal of Construction Engineering and Management pp. 351-358. 